\title{
Using WhatsApp in Teaching Chemistry and Biology to Tenth Graders
}

\author{
Marwan Abualrob \\ Arab American University, Palestine \\ ORCID: 0000-0002-5910-6235 \\ Safa Nazzal \\ Arab American University, Palestine \\ ORCID: 0000-0002-4308-6137
}

Received: 24 Aug 2019

Accepted: 23 Sep 2019

Published: 2 Nov 2019

\begin{abstract}
The aim of the study is to assess the extent to which WhatsApp Instant Messaging is used to teach chemistry and biology to the tenth-grade students. A mixed approach was used, whereby the authors drew on the content analysis model to analyze quantitative data. The sample consisted of 28 Palestinian tenth-grade students and their teachers, who used WhatsApp Instant Messaging for four months (the Spring semester of 2019). The collected data was divided into four categories: the nature of the message (instructional, organizational, or social); the form of the message (texts, pictures/graphs, voice recordings, videos, or link-sharing); the direction of communication flow (from a teacher to a student, from a student to a teacher, from a student to a student, or from a teacher to a teacher); and knowledge exchange. Our findings suggest that WhatsApp is used more for noninstructional purposes- particularly socialization- yet the portion of instruction-related messages was somehow enough to predict more effective future use of the application for teaching/learning purposes.
\end{abstract}

Keywords: WhatsApp, instant messaging, tenth grade, teaching/learning chemistry and biology

\section{INTRODUCTION}

Modern internet technologies have helped redefine the educational landscape around the world, and today teachers and learners are witnessing a paradigm shift based on e-learning, which is now slinking persistently through schools. E-learning is a modern method that can be used as a learning tool which utilizes technological applications such as text messaging, images, audio and video. One goal is connecting teachers and students beyond the classroom environment, making it easier to reach diverse learning sources, no matter the time, no matter the place. This is linked to learning being a result of social interactions in different collaborative contexts. E-learning employs various approaches across different contexts and social interaction situations, thus creating, among other things, a learning environment free from restrictions.

In the past few years, we have seen virtual social networks proliferating at full tilt, gaining more and more popularity and becoming part and parcel of today's life. Some people have seen in them potentials beyond the mere building of social relationships or contacting with friends. Because such networks allow users to share ideas and digital content, people have started using 
them for educational purposes. Many secondary school students, and teachers alike, have come to understand the benefits that social network platforms can offer, and thus they have started to use them for purposes other than socializing (Asterhan \& Rosenberg, 2015). Of course, the first candidate is WhatsApp, an application that enables school students to connect with their classmates or teachers at any convenient time to exchange information and instructions via either instant messaging, phone calls or even video calls. By late 2017, WhatsApp had reported around 1.5 billion as active users of the application around the globe (Constine, 2018).

One of the advantages of WhatsApp is enhancing communication. WhatsApp can provide a tool for more consistent and smoother communication between students and teachers, thus creating new venues of education. Teachers are often pressured to cover materials that might be disproportional to the time allocated for each class (arguably owing to the fact that some poorly-performing students need more time for each individual task, which makes the teacher rush to do the rest of tasks under time pressure). WhatsApp also enables immediate synchronous communication, and it is easily accessible by people, including school students and teachers. The application is different from other social networks in that it maintains the privacy of the people involved, and things they exchange do not go public, as in the case of Facebook, for example.

In 2018, there were 3.7 million monthly active WhatsApp users (or $84 \%$ of internet users) in Palestine (iPoke, 2018). We now know that students use social networks, including WhatsApp, for communicating; yet we know little about the nature of this communication. The present effort is an exploration of why and how students use WhatsApp and whether they use it for education purposes. We look at a repertoire of messages between students themselves and between students and their teachers, and accordingly sort out the content into themes pertaining to both social life and learning/teaching purposes. The present study seeks in particular to answer the following questions: How can WhatsApp be useful to students? Can students and school teachers cooperate to devise safe ways by which the tool can help learners bridge the gaps in their school learning? What is the nature of WhatsApp communication in a teaching/learning environment? This should hopefully be an addition to the already existing literature on tapping social networking resources to supplement classroom activities.

\section{LITERATURE REVIEW}

Social constructivist theory in education seeks to improve social interactions among students and foster shared knowledge (Vygotsky, 1978). At the heart of the theory lies the conviction that knowledge-building depends on the social interactions in the environment around children and teenagers. According to Vygotsky, biological growth is often accompanied by knowledgebuilding processes; and therefore it is important that parents and schools be cognizant of the social factors that influence the mental growth of children.

In today's world, keeping up with technologies that help us adapt to our surroundings is integral to our social development as humans. In 2004, George Siemens introduced a paradigm he named "constructivism." Simply put, it is an approach that places special emphasis on the role of the socio-cultural contexts in the learning process. Since the talk is about the digital age, then it is legitimate to assume that modern technologies have implications on the entire process of education. This is the realm where the debate on social networking applications becomes quite relevant. For around 10 years now, people have been using WhatsApp to connect with their phone contacts, often for socializing and business purposes. Recently, however, some people have seen potentials in WhatsApp as a learning medium. 
Social networking applications are platforms that make it possible for people to create or share content through multi-side communication environment (Boyd \& Ellison, 2007). The aim of such applications is multifaceted: enhancing communication, strengthening cooperation, reinforcing creativity, and fostering convergence (Friedman \& Friedman, 2013). Literature in the field has shown that the use of social networking applications as learning tools can support learning, energize learners, improve interaction and motivate learners for further exploration (See, for example, Plana et al., 2013; Smit, 2011).

The quality of an application helps build patterns of communication and the nature of the relationship between people involved (Robert \& Dennis, 2005). This should be true for WhatsApp and other social networking platforms. This study is an effort into understanding how WhatsApp is used by tenth graders and their teachers in Palestine.

Much existing literature on using WhatsApp in educational settings is focused on perceptions of users or observers, ethical and social issues associated with the use of the application, as well as the real benefit from it in the learning process (See, for example, Fewkes \& McCabe, 2012; Smith, 2016). At least in Palestine, very few studies have explored the true nature of WhatsApp communication between students or between students and teachers. The present effort is intended to add to the recent research initiatives (See, for example, Schwarz \& Caduri, 2016) carried out to identify the methods by which secondary school teachers and students use undirected (spontaneous) WhatsApp messaging service for instructional purposes.

\section{METHODOLOGY}

Between February 3 and June 1, 2019, we carried out an analytical interventional study at Merkeh Secondary School for Girls, Palestine. The study sought to assess the potential of elearning methods in supporting the school curriculum. We purposively selected that school because the local community there is conservative, with girls having narrow margins for using social networks. Right before starting our study, we arranged for a meeting with the target students and their parents after we had obtained a permission from the Ministry of Education. In that meeting, we told parents about our initiative and the goal behind it. At the end of the meeting, we asked them to complete a questionnaire that was designed to measure the determinants and obstacles to using WhatsApp as perceived by the target students and their parents. Later in the day, we selected a sample of 28 female students from the 10th grade to be the subjects of the study. We (with one of us being the biology teacher at that school) gave the subjects 3 G SIM cards and told them that they would be using those SIMs to communicate with their chemistry and biology teachers for instructional purposes. To this end, we set up a closed group, with only members being able to see the content of the group's posts.

We used a mixed approach, whereby the content analysis model was used to analyse quantitative data. The study subjects and their teachers used WhatsApp Instant Messaging for four months (the Spring semester of 2019). The collected data was divided by type into four categories: the nature of the message (instructional, organizational, or social); the form of the message (texts, voice recordings, videos, or link-sharing); the direction of communication flow (from a teacher to a student, from a student to a teacher, from a student to a student, or from a teacher to a teacher); and knowledge exchange. Because of the sheer volume of messages, we focused only on a sample of communication exchanged between March 28 and April 28, 2019, when students had been around two months` into the Spring semester.

To have an in-depth look into how school students and their teachers use WhatsApp, we collected data from students and teachers' WhatsApp log, which was kept intact. The 
quantitative dimension of the study (i.e., the frequency of an item: nature, form, direction, knowledge exchange) was meant to measure the frequency of messages and the weight of each category identified in the qualitative analysis.

\section{ANALYSIS}

To have an in-depth look into how school students and their teachers used WhatsApp, we collected data from students and teachers' log, which was kept intact, including texts, videos, pictures, voice messages, emoji images and special characters. The quantitative dimension of the study (i.e., the frequency of an item: nature, form, direction, knowledge exchange) was meant to measure the frequency of messages and the weight of each category identified in the qualitative analysis.

\section{First: Nature of the Messages}

From the analysis, several categories as to the nature of the messages were identified:

\section{Instructional}

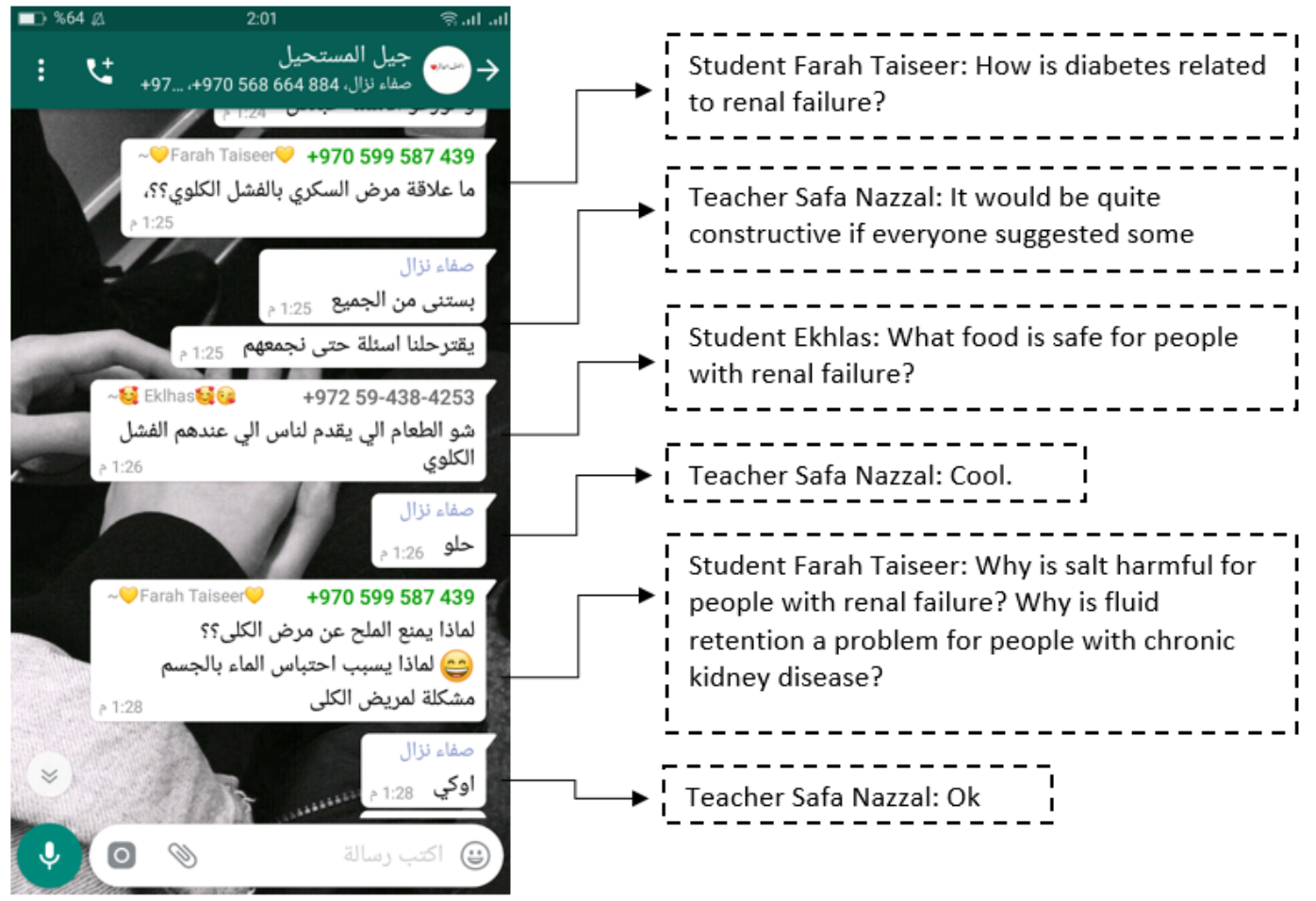

Figure 1. Instructional Messages Exchanged Involving Both Teachers and Students

The instructional messages exchanged took several forms. First, there were questions the two teachers asked their students, in order to nurture in them the skill of searching for answers. Second, we also saw students soliciting answers from their teachers to specific questions. Third, sometimes, students asked their classmates about scientific phenomena, to which they received answers from both the teachers and other students who are familiar with the topic in question. 


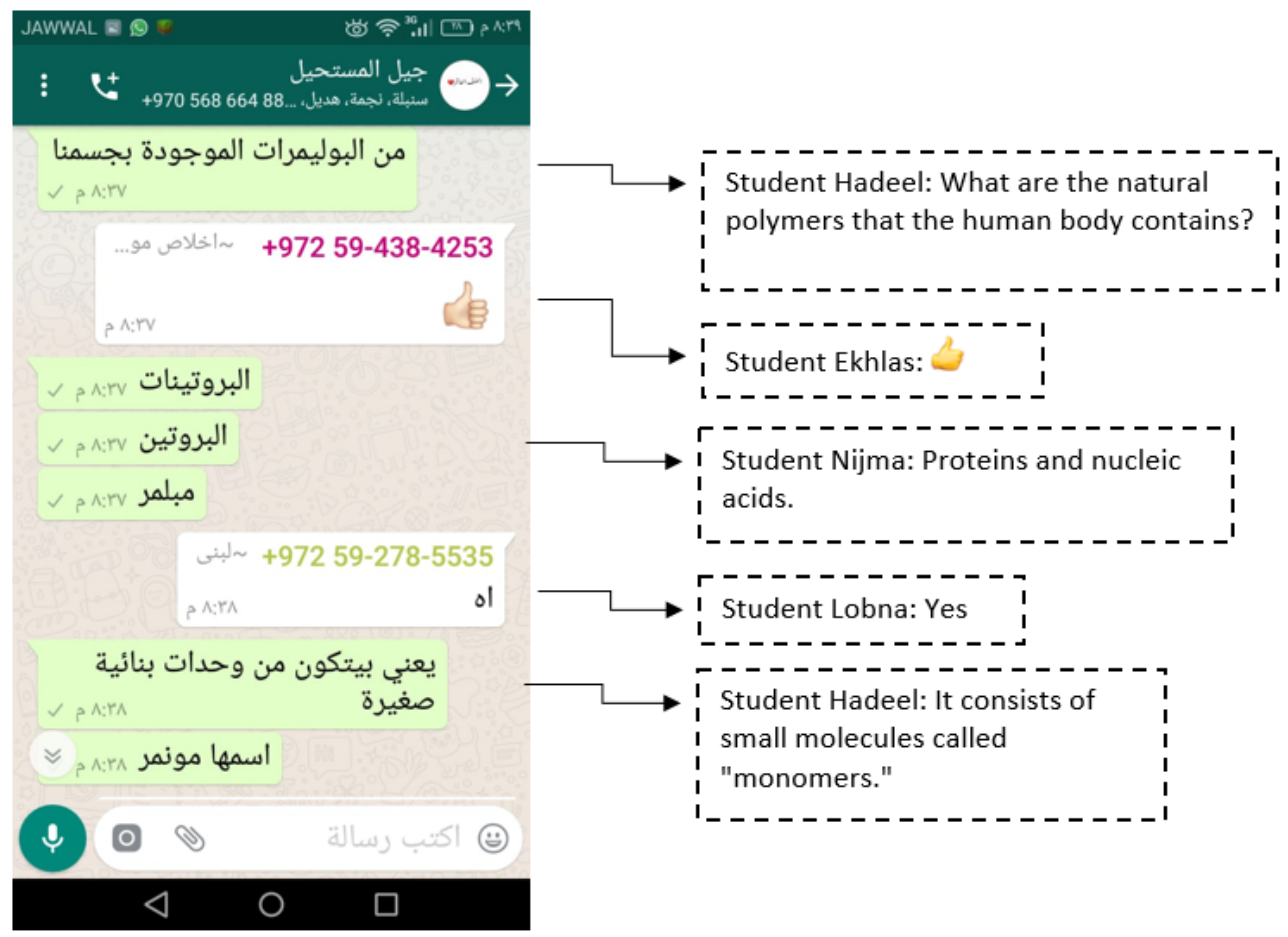

Figure 2. Instructional Messages Exchanged Involving Students Only

Interestingly, the answers prompted further exchanges, which enriched the discussion and helped eliminate conceptual errors- common among students of biology and chemistry.

\section{Social}

Even though the students were informed beforehand of the primary purpose of the experiment (i.e. using WhatsApp for educational purposes), the analysis revealed that a lot of the messages exchanged between students were social in nature: salutation, jokes, entertainment, issues of shared concerns, and having fun.

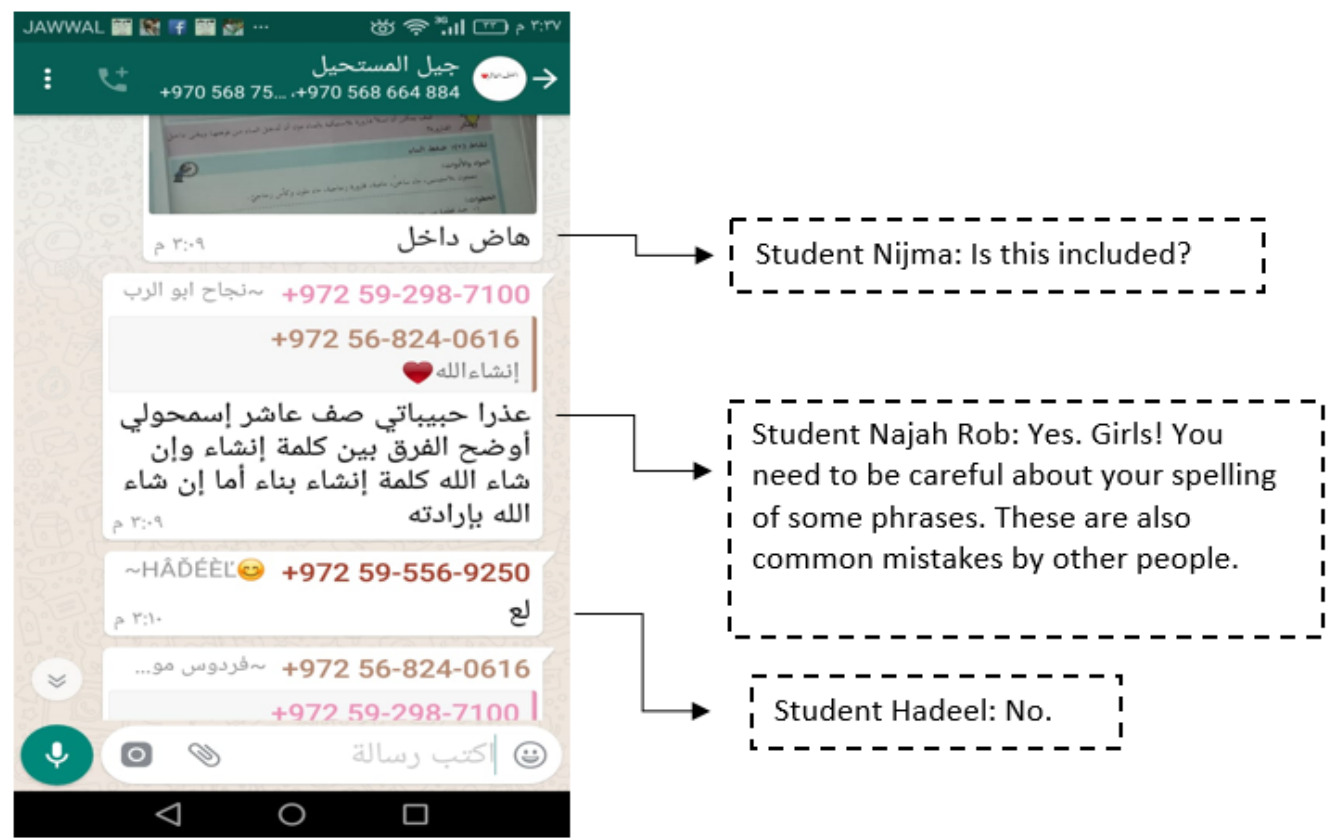

Figure 3. Social Messages Exchanged Involving Students Only 


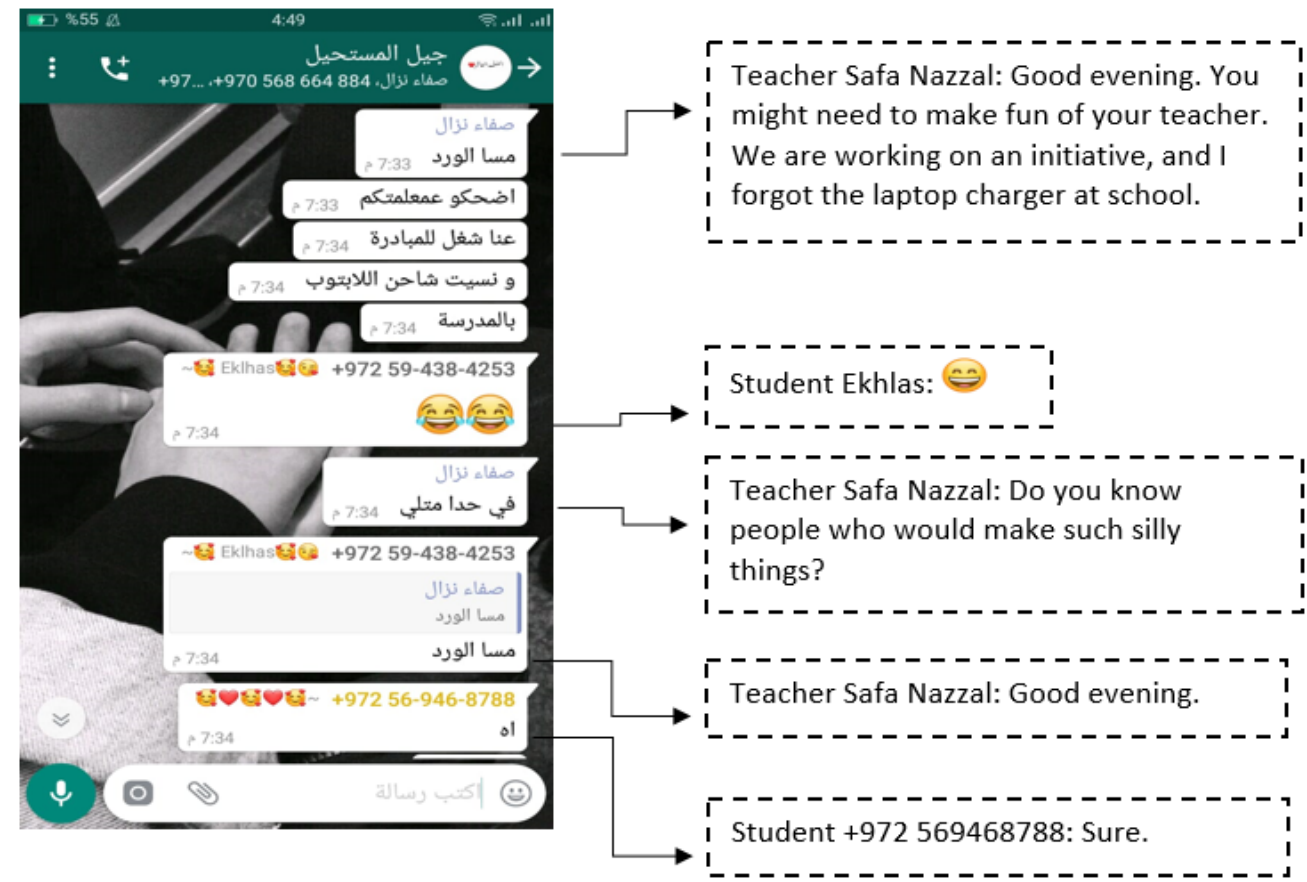

Figure 4. Social Messages Exchanged Involving Both Teachers and Students

\section{Organizational}

The analysis revealed many posts which involved exchange of organizational messages, such as inquiries about the date of examinations, the date of the open day, the date of the school trip, the discipline within the school.

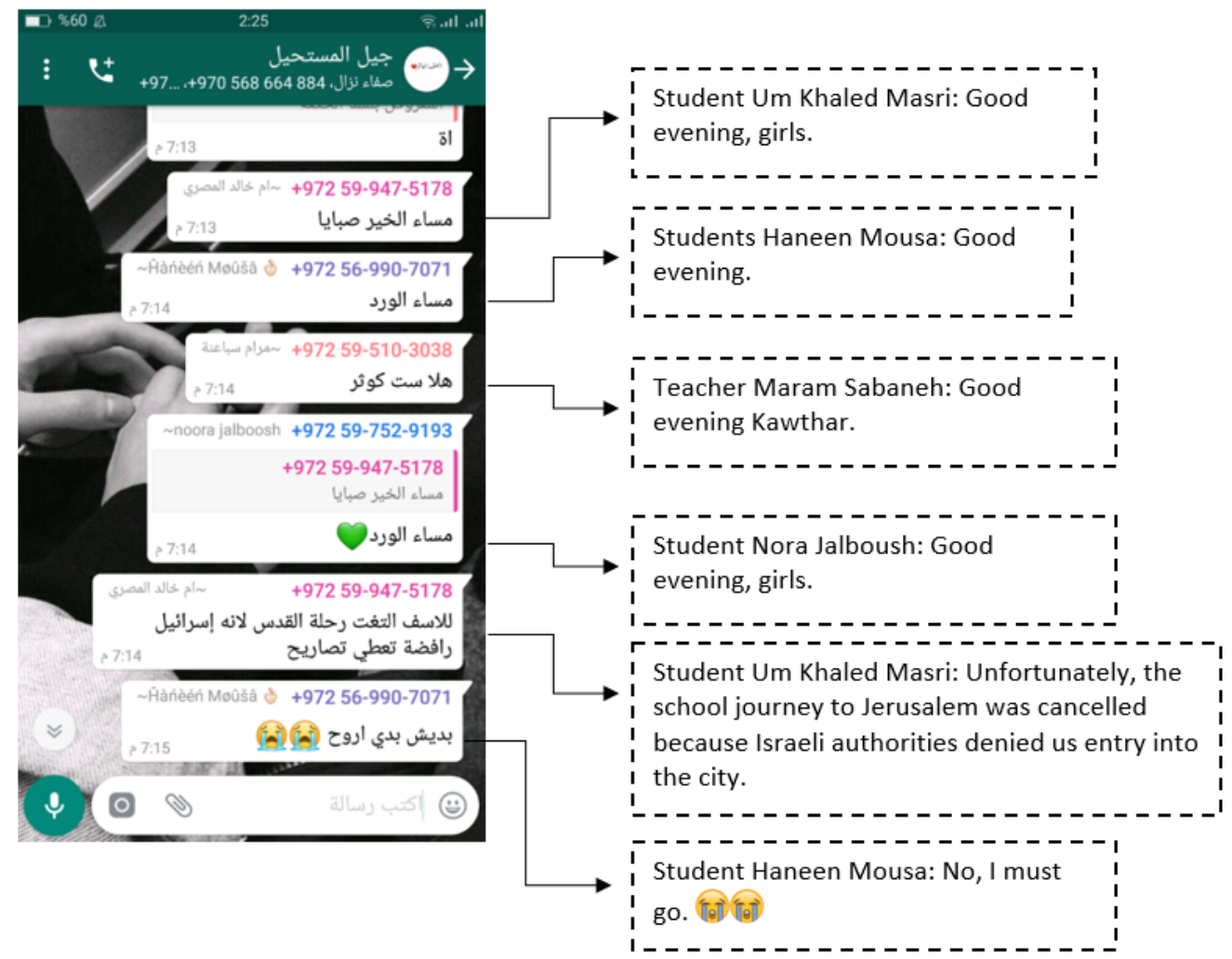

Figure 5. Organizational Messages Exchanged 
Table 1. Nature of the Messages

\begin{tabular}{ccc}
\hline Nature of the messages & Repetition & Percentage \\
\hline Instructional & 596 & $26 \%$ \\
\hline Social & 1040 & $46 \%$ \\
\hline Organizational & 637 & $28 \%$ \\
\hline
\end{tabular}

As clearly shown in Table 1, the subjects used WhatsApp messaging service more for socializing although the main objective of setting up the group was to support the instructional process. This shouldn't make us raise our eyebrows. For the subjects, that was probably their first encounter with WhatsApp, which is, by nature, a social networking platform. Naturally, transforming the use of WhatsApp from a social network to a learning environment is not an expeditious process; it needs time and more efforts.

\section{Second: Forms of the Messages}

Our analysis of the WhatsApp log also revealed that the messages took different forms: voice recordings, videos and link-sharing.

\section{Texts}

Text messages constituted the largest part of the messages exchanged within the group. The posts of this form were largely questions, answers and didactic statements:

- Student: "Did you know that the black spots on bananas produce a substance called "antitumor" that can destroy cancer cells?"

- Biology teacher: "Do you know what the shortest and the tallest bones in the human body are? I need to see answers from all."

Student 1: "The femur"

Biology Teacher: "Exactly"

Student 2: "The one in the middle ear, the stapes"

Biology Teacher: "This is very clever."

- Student asking: "How to get rid of calcification?"

Student answering: "By using vinegar and water."

Chemistry Teacher: "Brilliant."

Text messaging is the most frequently used form, as it only needs a simple tap on "New Chat", writing a message and pressing "Send". The focus on text messaging is natural, as writing should be easy and fast, and it doesn't need professional-level knowledge of the application (See Table 2).

Table 2. Form of the Messages

\begin{tabular}{ccc}
\hline Form of the message & Frequency & Percentage \\
\hline Texts & 2201 & $96.6 \%$ \\
\hline Pictures & 36 & $1.6 \%$ \\
\hline Videos & 10 & $0.4 \%$ \\
\hline Voice recordings & 22 & $1 \%$ \\
\hline Link-sharing & 4 & $0.2 \%$ \\
\hline
\end{tabular}


Teachers used WhatsApp text messaging service to post short assignments and ask students to do them by using one of the features the platform offers. What is really interesting about WhatsApp is that it can offer us a combination of many features that other platforms cannot individually offer. The students must have found innovation in the experience, and thus most of them would eagerly take part and engage in the discussions. Rambe and Chipunza (2013) found that WhatsApp supported knowledge sharing between students, as well as between students and teachers. WhatsApp also helped students express their thoughts without restrictions typical in classrooms.

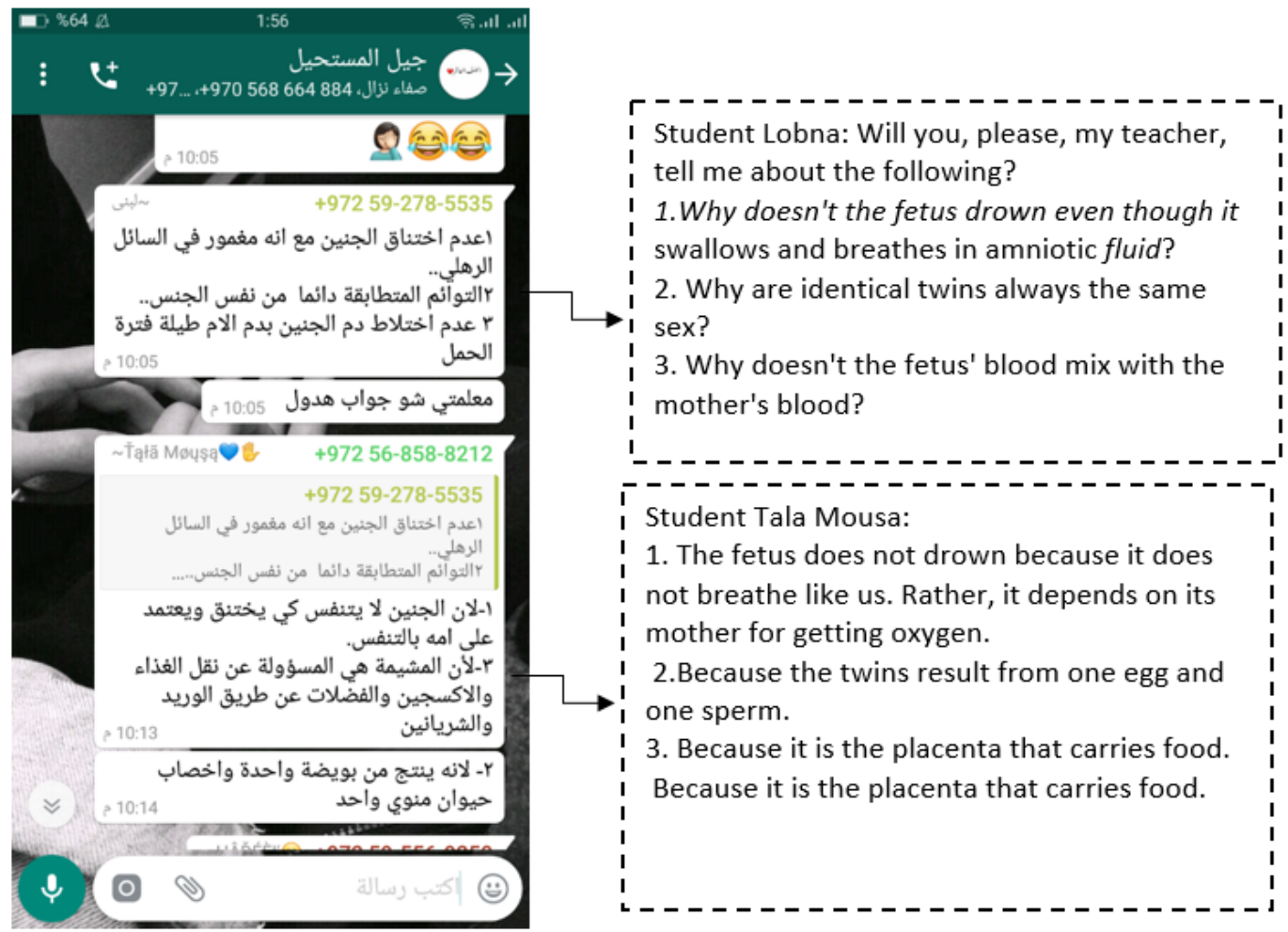

Figure 6. Text Messages

\section{Pictures/Graphs}

When used, the pictures were meant to show something that cannot be shown otherwise. Examples included pictures of the luteal phase of the estrous cycle, or the follicular phase of the estrous cycle in mammals; pictures of human skeleton with different constituents of the bone structure; pictures of a group of genes showing the structural formula; pictures of the nervous system with some captions and simple information; and a picture of the cycle of human waste (as shown in the attached log). This is followed by questions on the topic of the picture, which initiated discussions among the members of the group.

Very few pictures, however, were exchanged by the members of the group. Loading pictures requires more time, effort and competent-level use of WhatsApp features. What's more, students find it difficult to find an appropriate picture with relevance to the topic. This needs mining in specialized websites, which sometimes makes students quit the attempt. 


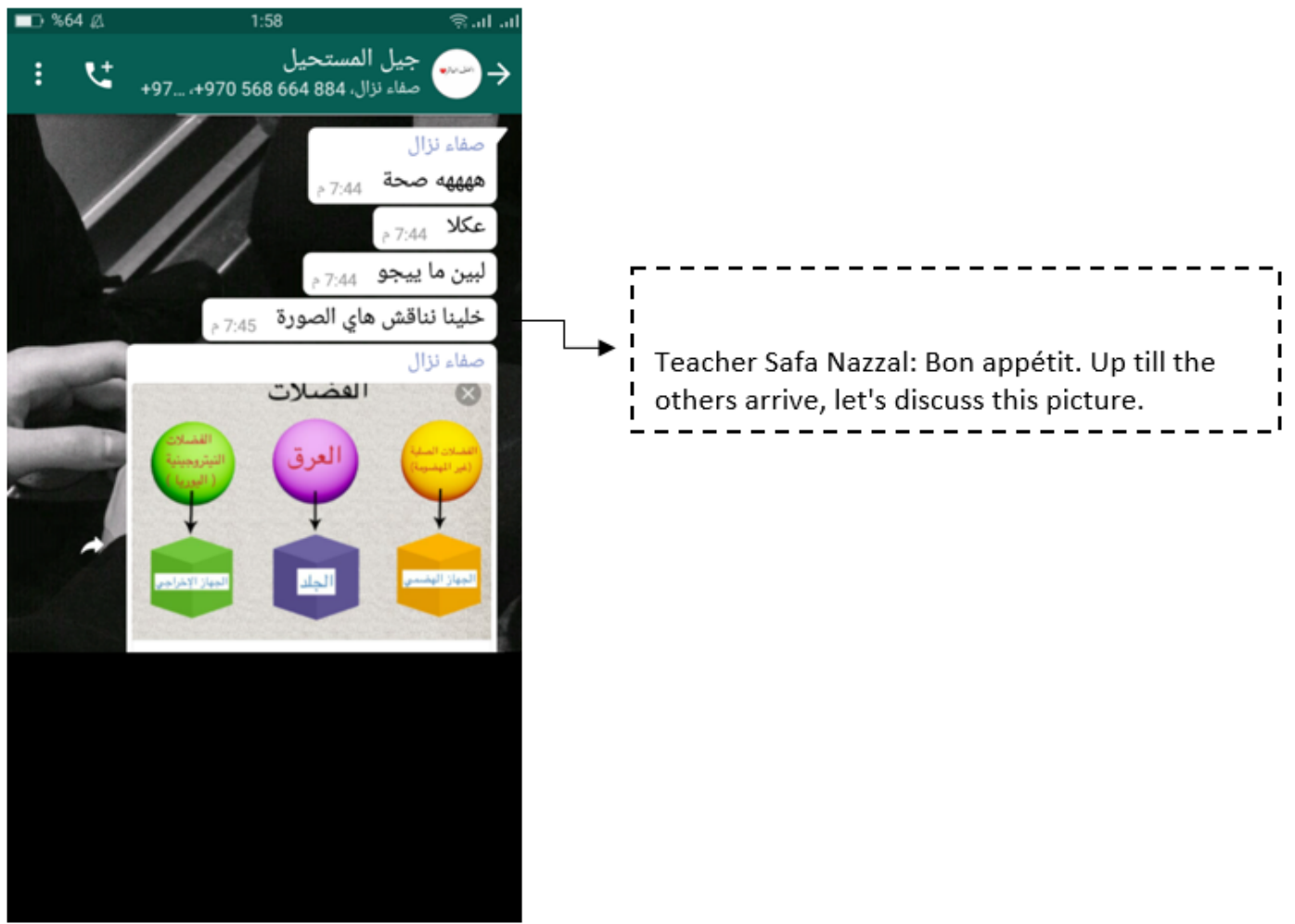

Figure 7. Picture / Graph Messages

\section{Videos}

Videos were not often used by the members, and when used they were very simple (for example, the differences between identical and non-identical twins). Unfortunately, the Palestinian curriculum is not supported by video clips and short films, which forces students to search for related videos in languages other than Arabic. This is daunting and time-consuming, but it also prompted some students to create their own videos, which motivated creativity and innovation. 


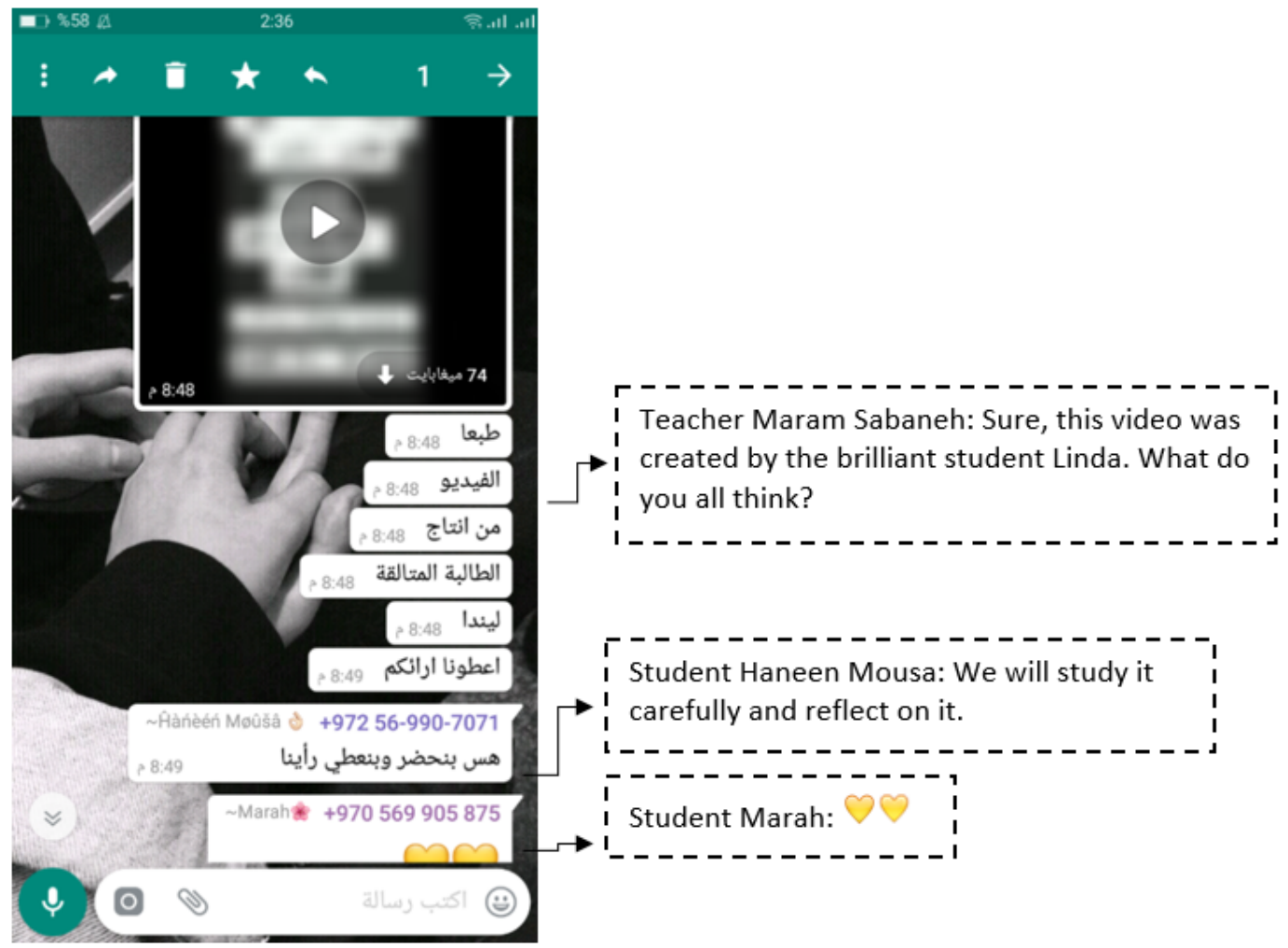

Figure 8. The Video Exchanged

\section{Voice messages}

This is the least used type of messaging, arguably because voice messages are very much sensitive to the social, cultural and religious traditions that impose restrictions on girls' use of the feature. It is important to remind the reader here that the research was done in a small village with a conservative community. 


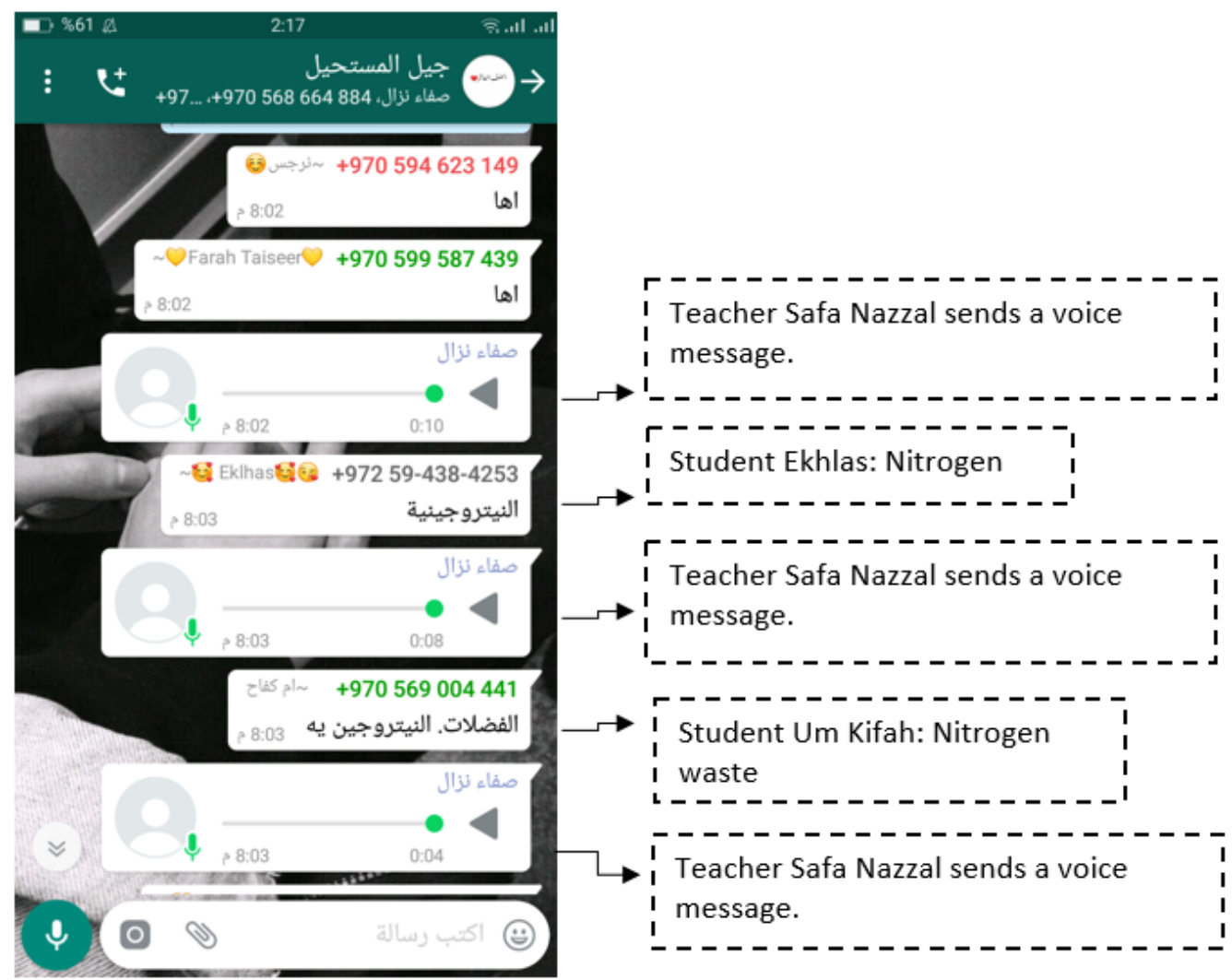

Figure 9. Voice Messages Exchanged

\section{Link-sharing}

Again link-sharing within the group was minimal, as the practice requires experience, training and search. Language might be a barrier in this regard. Usually, science-related websites are in English, and few Arabic-speaking tenth graders can fully understand scientific texts in English. Finding themselves caught between inadequate Arabic websites and the trouble understanding English websites, the students prefer to abandon link-sharing unless the website provides adequate, relevant information. This is a call for teachers to first use modern methods of teaching, second train their students on search skills, and third create, in collaboration with the Ministry of Education, websites and videos in support of the curriculum. (Note: When these students join Palestinian universities later, they receive instruction only in English). 


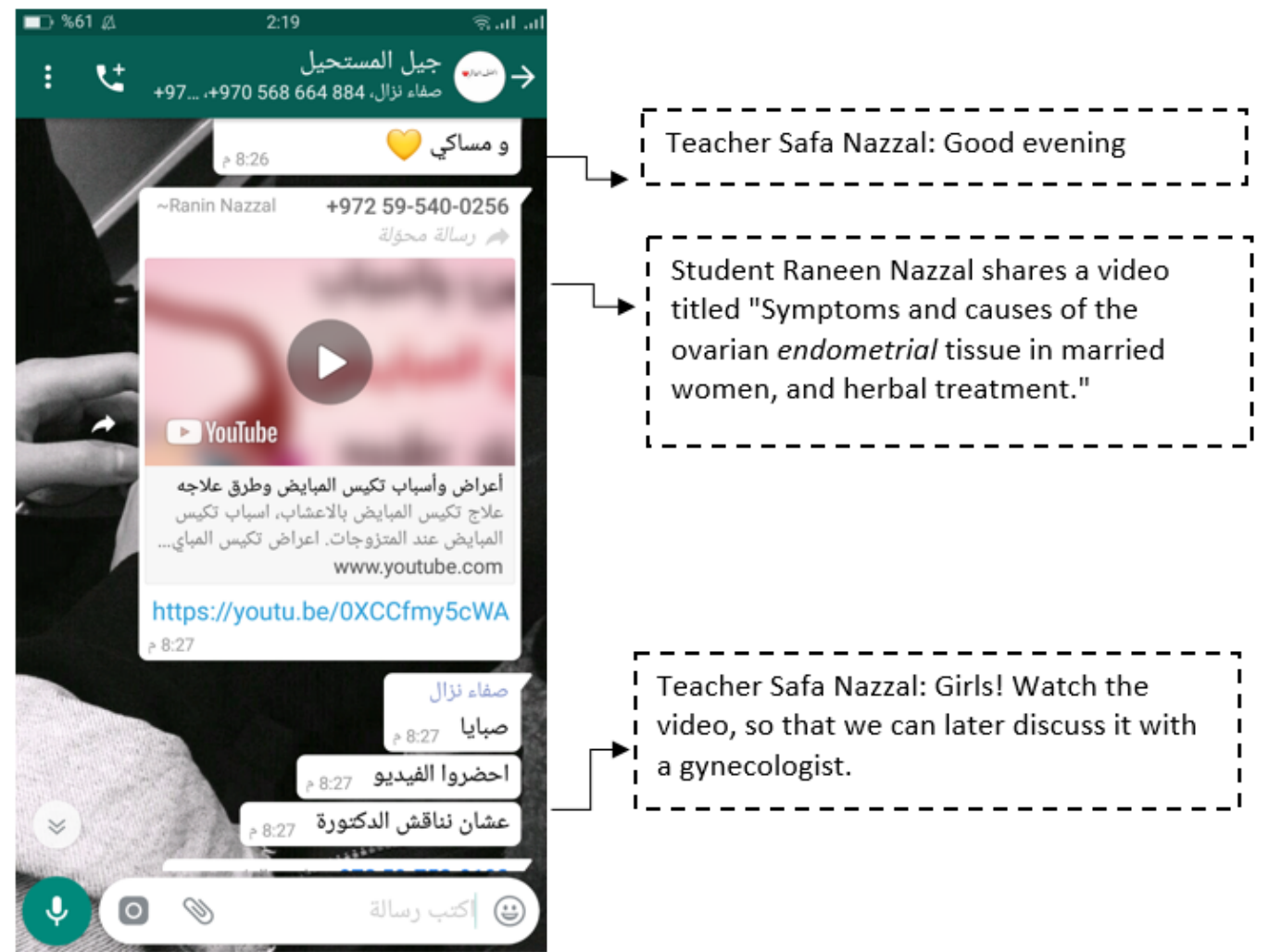

Figure 10. Link-sharing Messages Exchanged

\section{Third: Direction of Communication Flow}

Table 3 shows four directions of the communication flow, with the most frequent being the student-teacher and the least being the teacher-teacher direction.

Table 3. Direction of Communication Flow

\begin{tabular}{ccc}
\hline Direction of communication flow & Frequency & Percentage \\
\hline Teacher-student & 927 & $40.6 \%$ \\
\hline Student-teacher & 1200 & $52.8 \%$ \\
\hline Student-student & 73 & $5.8 \%$ \\
\hline Teacher-teacher & 13 & $0.6 \%$ \\
\hline
\end{tabular}

\section{From a teacher to a student}

This is the most traditional channel, typical of teacher-centered education where students put all of their focus on the teacher who gives instructions and students respond, the kind of "Girls! Look at the picture and answer questions." 


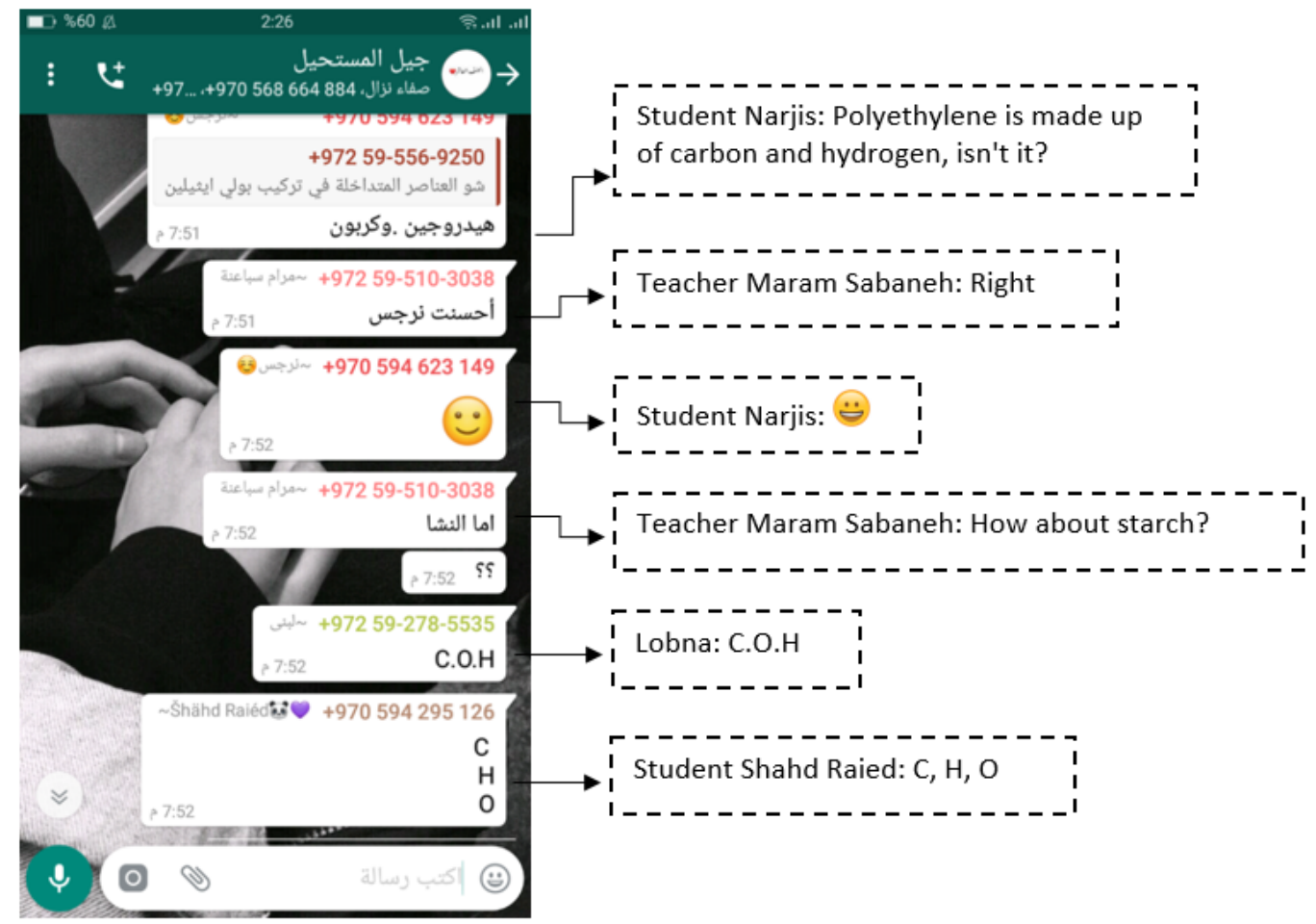

Figure 11. Messages from Teachers to Students

WhatsApp can be used to transform the classroom. This transformation should, however, be controlled by the teacher, lest things develop into chaos. The teacher might, for example, share a link to an article with students, and then the teacher asks questions to which students can respond. The article might be an extended reading that adds or elaborates on a lesson already in the textbook. When students and the teacher physically meet, they can only have further discussion and do the tasks in the textbook. 


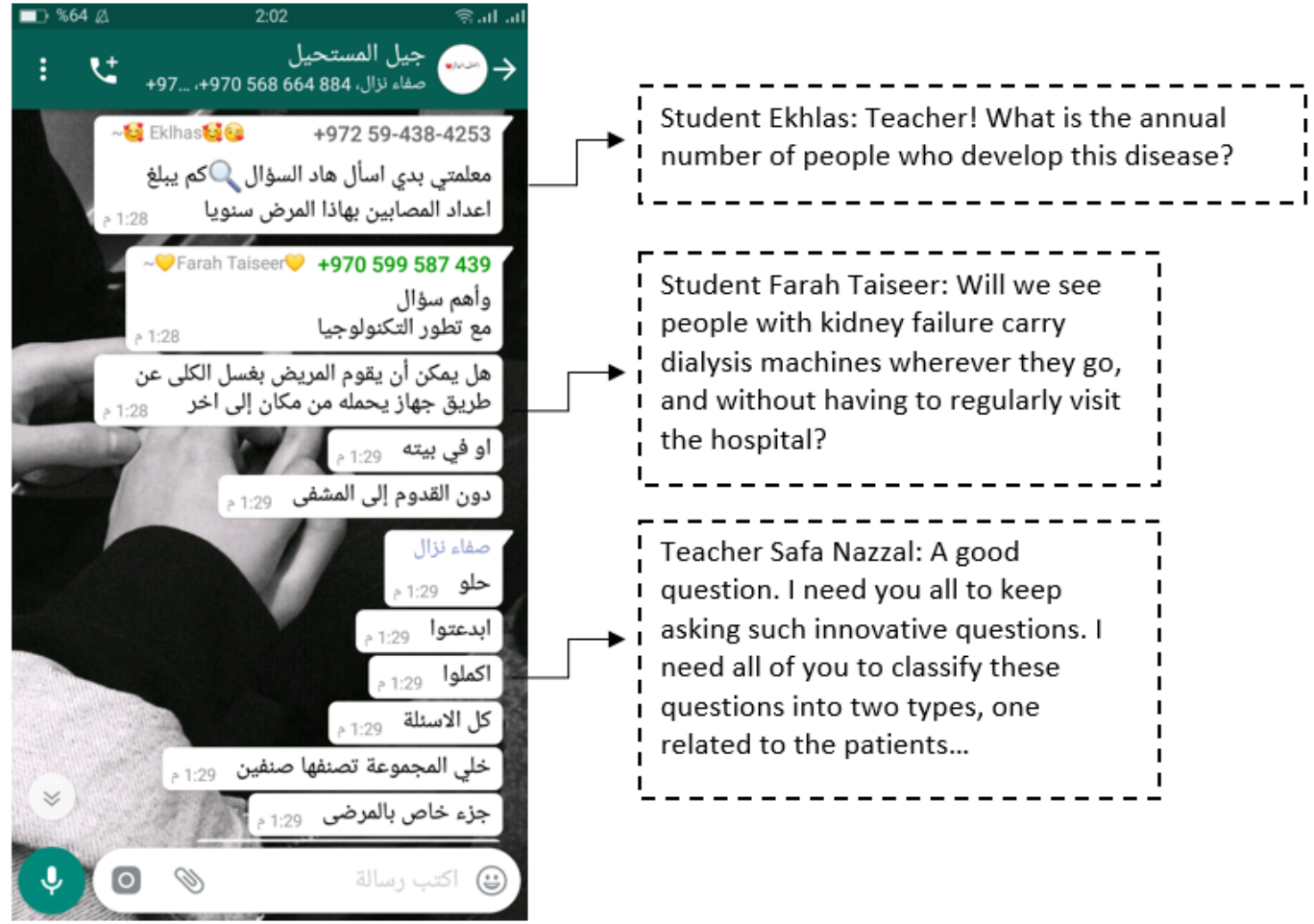

Figure 12. Messages from Students to Teachers

\section{From a student to a teacher}

This type of communication flow is very common, and it is a simulation of the classroom environment, where the students are used to asking their teachers about things they don't understand. This type also implies that students only trust their teachers, especially when the answer to the question is not explicit in the curriculum. WhatsApp as a learning tool is particularly helpful for unconfident, self-effacing students. On WhatsApp, these students can be very open communicators. The confidence they build on WhatsApp will likely help them be more engaged in classroom activities and create in them more positive attitudes toward the learning process.

\section{From a student to a student}

The main goal of using WhatsApp in education is encouraging student engagement and studentcentered education. It was, however, sad to find out that this direction was not as significant as the ones between the students and the teachers. Psychology here walks into the scene to provide interpretations: a student who prefers to ask a teacher and refrains from asking a classmate about a concept or a phenomenon does not want to appear ignorant in front of her classmates, while she has no issue asking the locus of trust, the teacher. If anything, the teachers are still using traditional methods, and they have yet to nurture in their students the value of seeking knowledge from any source available, be it a teacher, a student, a relative, etc. 


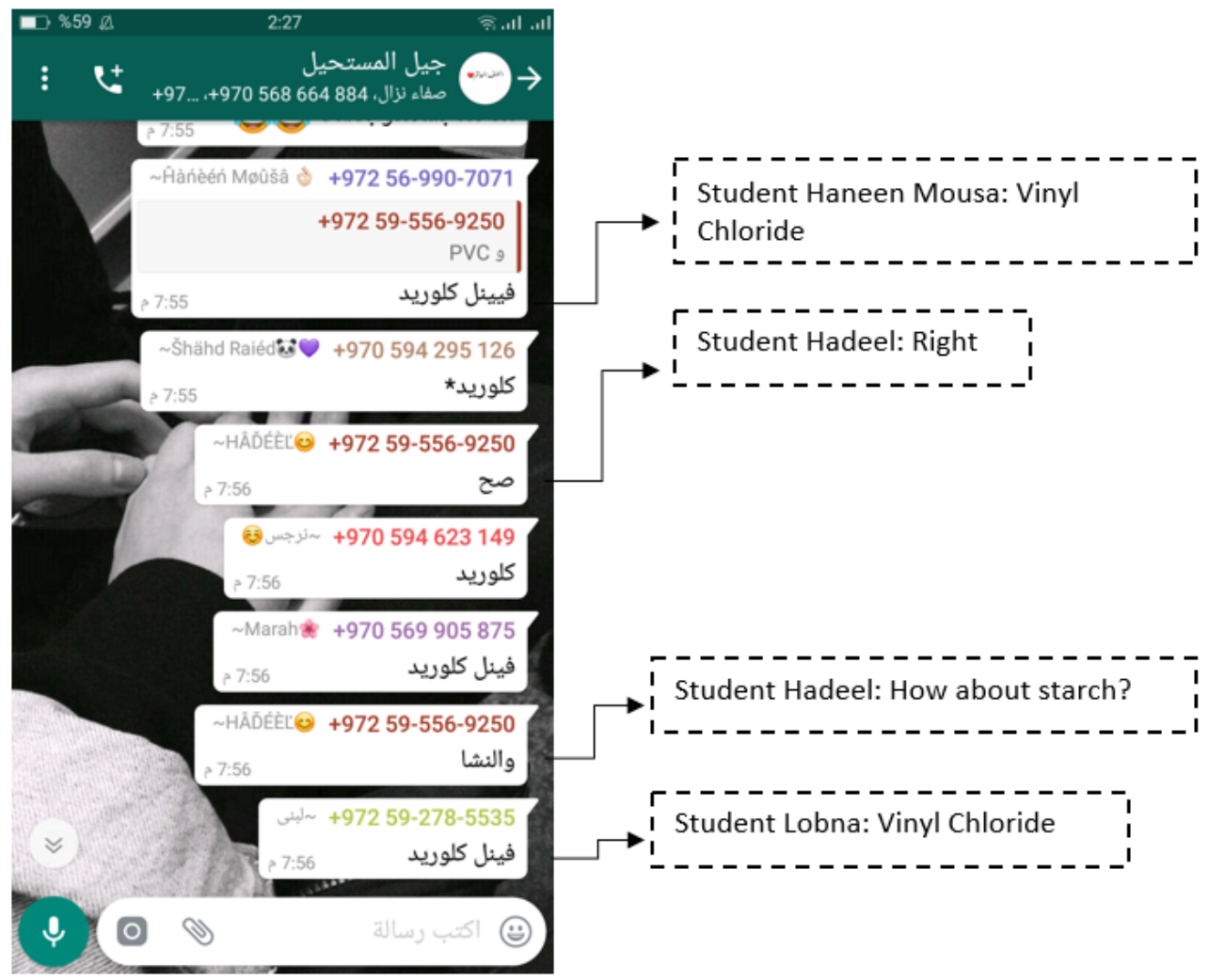

Figure 13. Messages Students Exchanged (1)

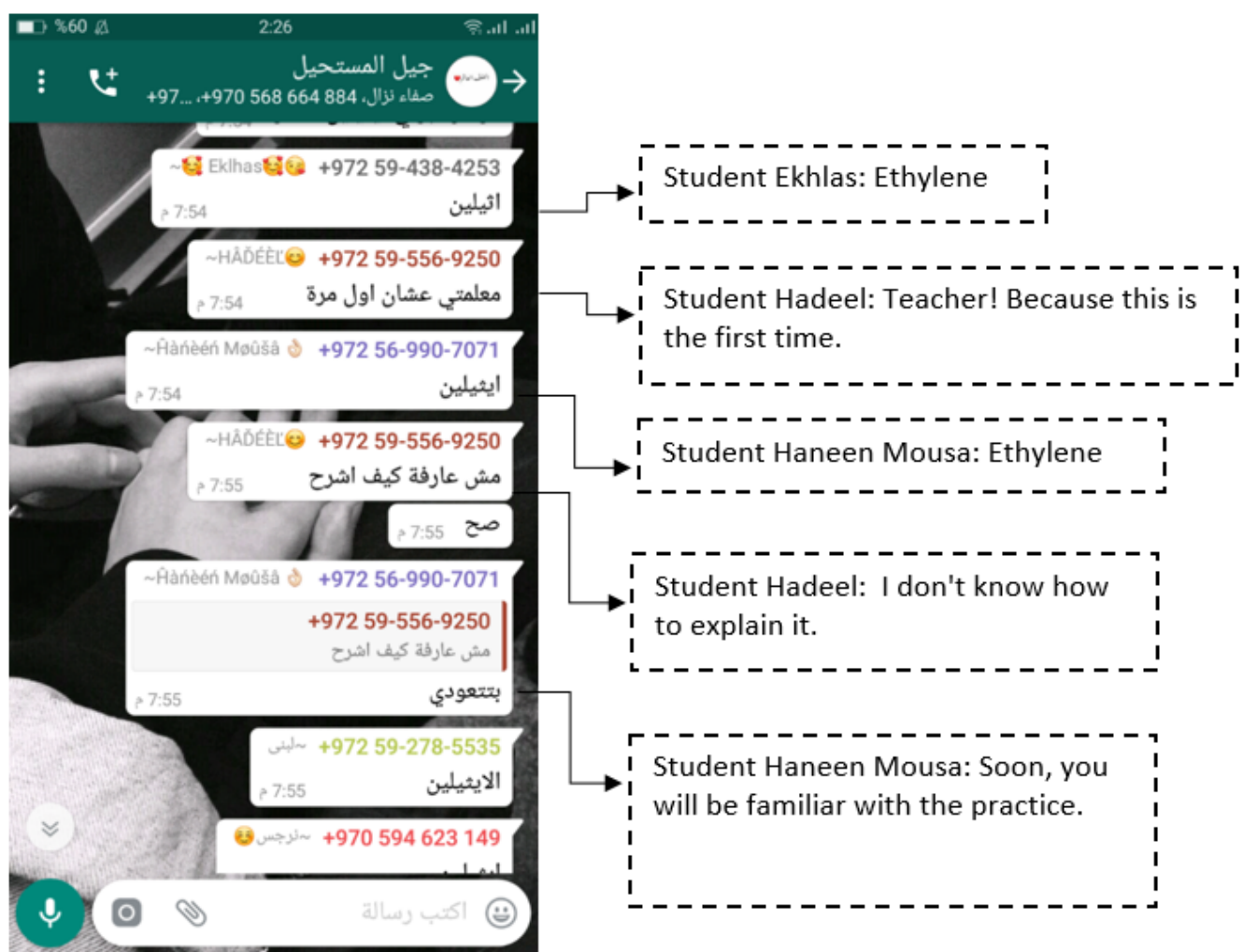

Figure 14. Messages Students Exchanged (2) 


\section{From a teacher to a teacher}

The log shows very few messages exchanged by the two teachers. To a certain extent, we had expected this to be the case given the fact that the two teachers teach different subjects, and that being the case, there is very little to talk about except when the two subjects overlap, such as when discussing natural polymers and their relationship to animals and plants. In a bigger school, with more than one teacher teaching the same subject, such communication is likely to be much more significant, as cooperation would then be absolutely indispensable to delivering the curriculum.

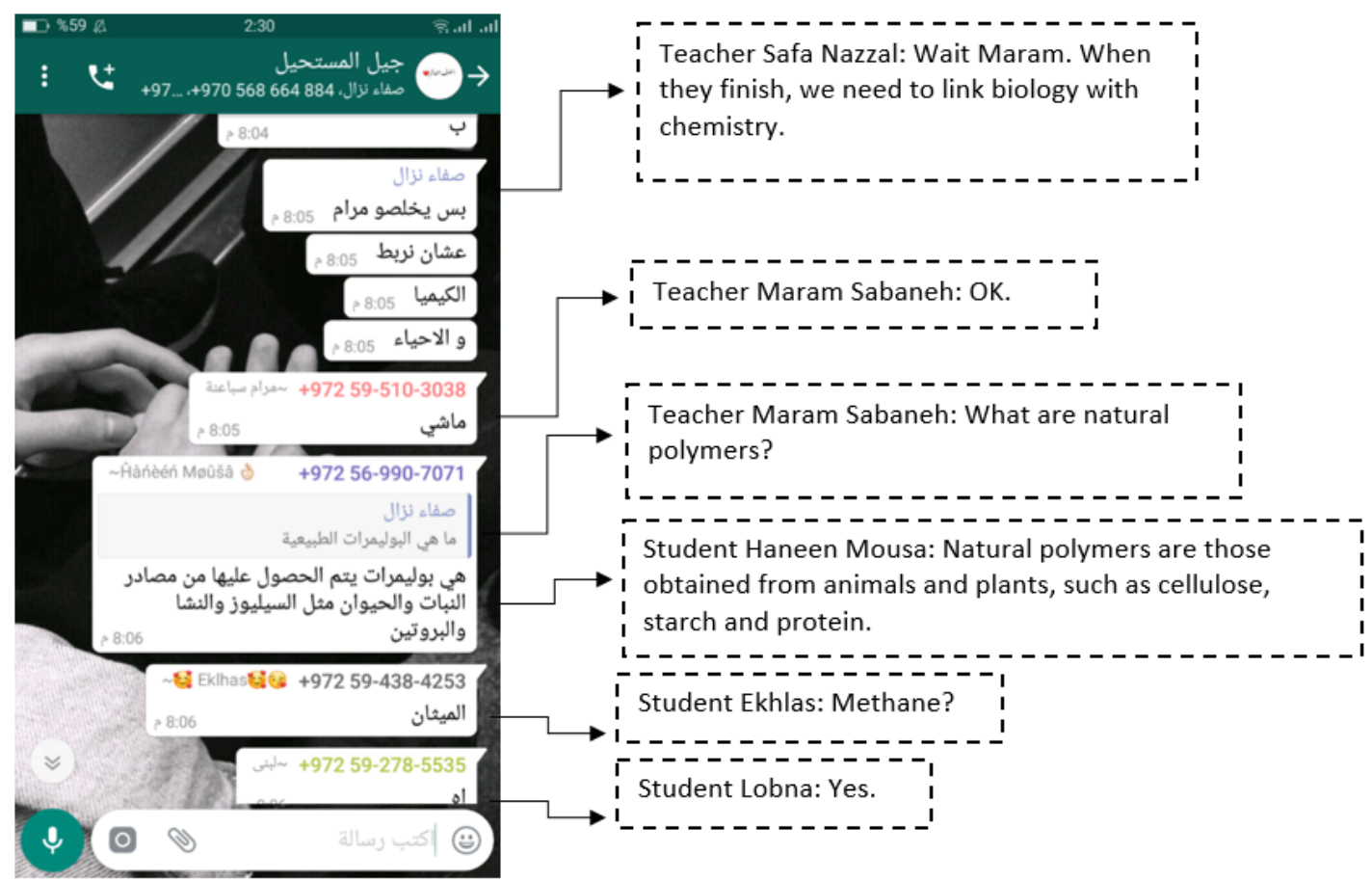

Figure 15. Messages Teachers Exchanged

\section{Fourth: Knowledge Exchange}

The analysis brought forth three categories of knowledge as illustrated in Table 4.

Table 4. Level of knowledge

\begin{tabular}{llcc}
\hline \multicolumn{2}{c}{ Knowledge } & Frequency & Percentage \\
\hline \multirow{2}{*}{ Level of knowledge } & Surface & 27 & $26 \%$ \\
\cline { 2 - 4 } & Basic & 38 & $37 \%$ \\
\cline { 2 - 4 } & Deep & 38 & $37 \%$ \\
\hline \multirow{2}{*}{$\begin{array}{l}\text { Relevance to the } \\
\text { curriculum }\end{array}$} & Relevant & 98 & $95 \%$ \\
\cline { 2 - 4 } Relevance to life & Irrelevant & 5 & $5 \%$ \\
\cline { 2 - 4 } & Relevant & 78 & $24 \%$ \\
\hline
\end{tabular}

\section{Level of knowledge (surface, basic and deep)}

The messages established patterns of these levels, as in the examples below (arranged respectively): 


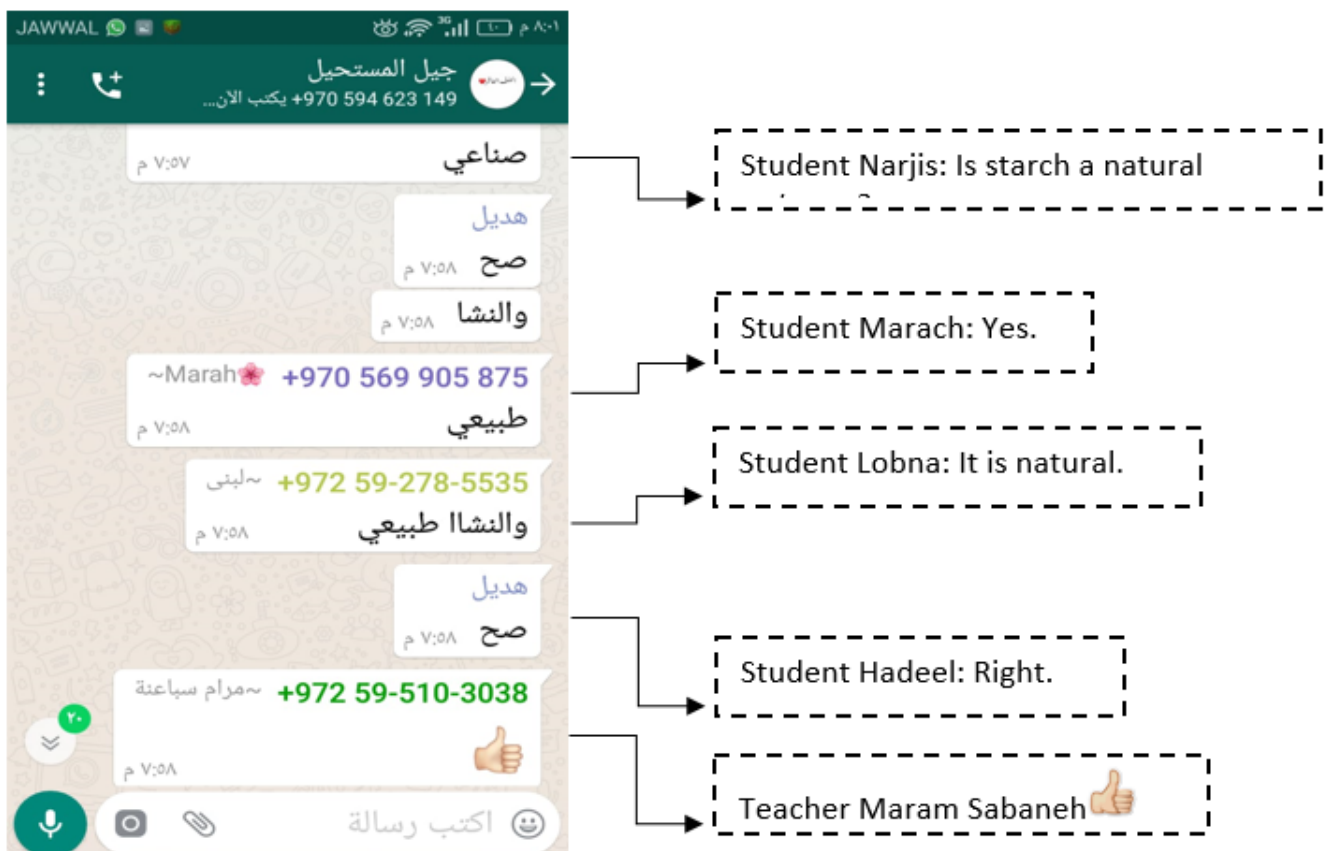
$\checkmark$
$\bigcirc$

\section{$\square$}

Figure 16. Surface Knowledge

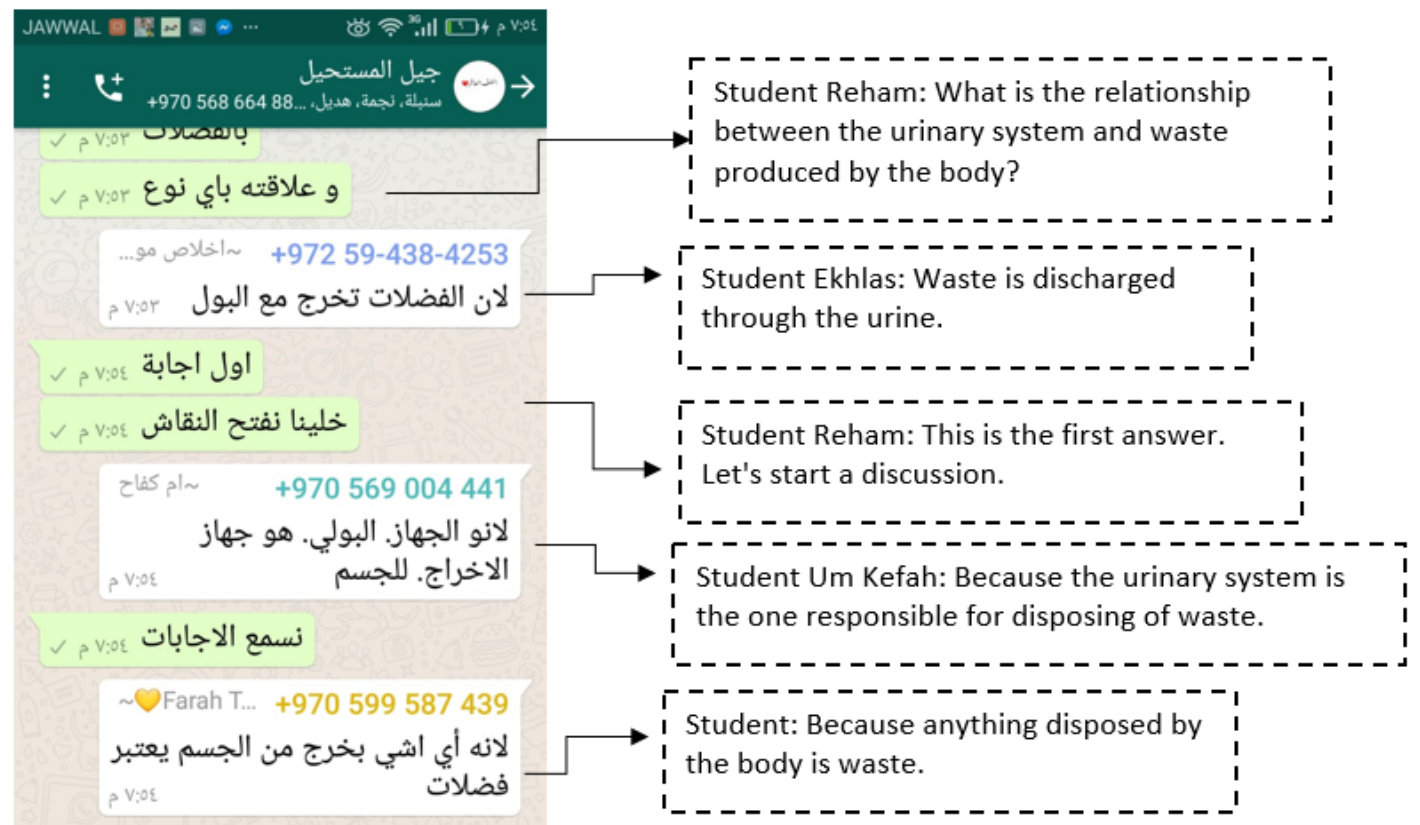

(4) 0 0 : : 0

Figure 17. Basic Knowledge 


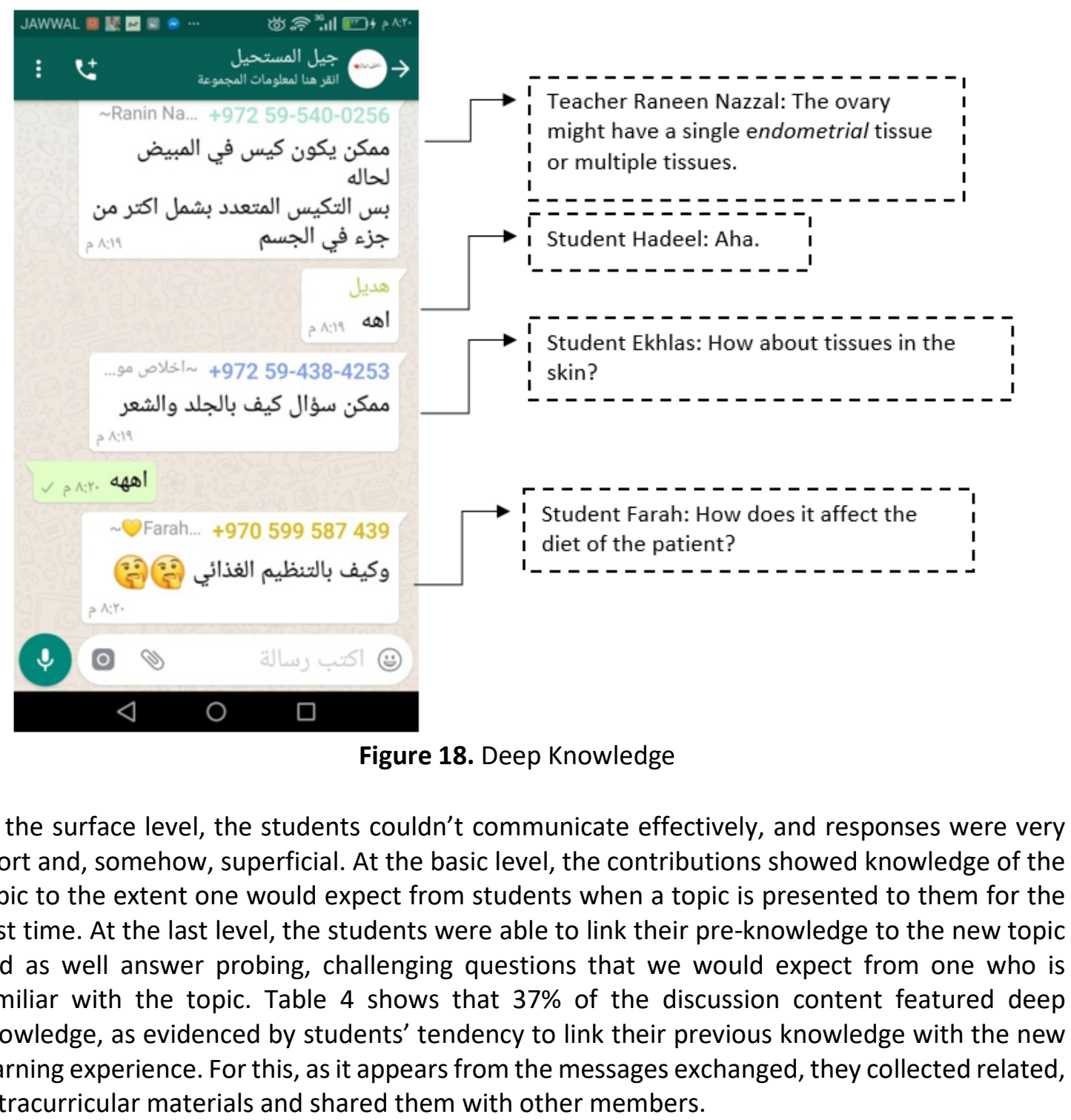

\section{Relevance to the curriculum}

The discussions by the WhatsApp group members showed some contributions with sufficient relevance to the curriculum and others with minimal or even zero relevance. As we mentioned earlier, WhatsApp is used as a platform for communication, and thus whatever information students exchange should be understood within this framework. Therefore, even with the latter case, there shouldn't be a problem as long as the objective is seeking knowledge. 


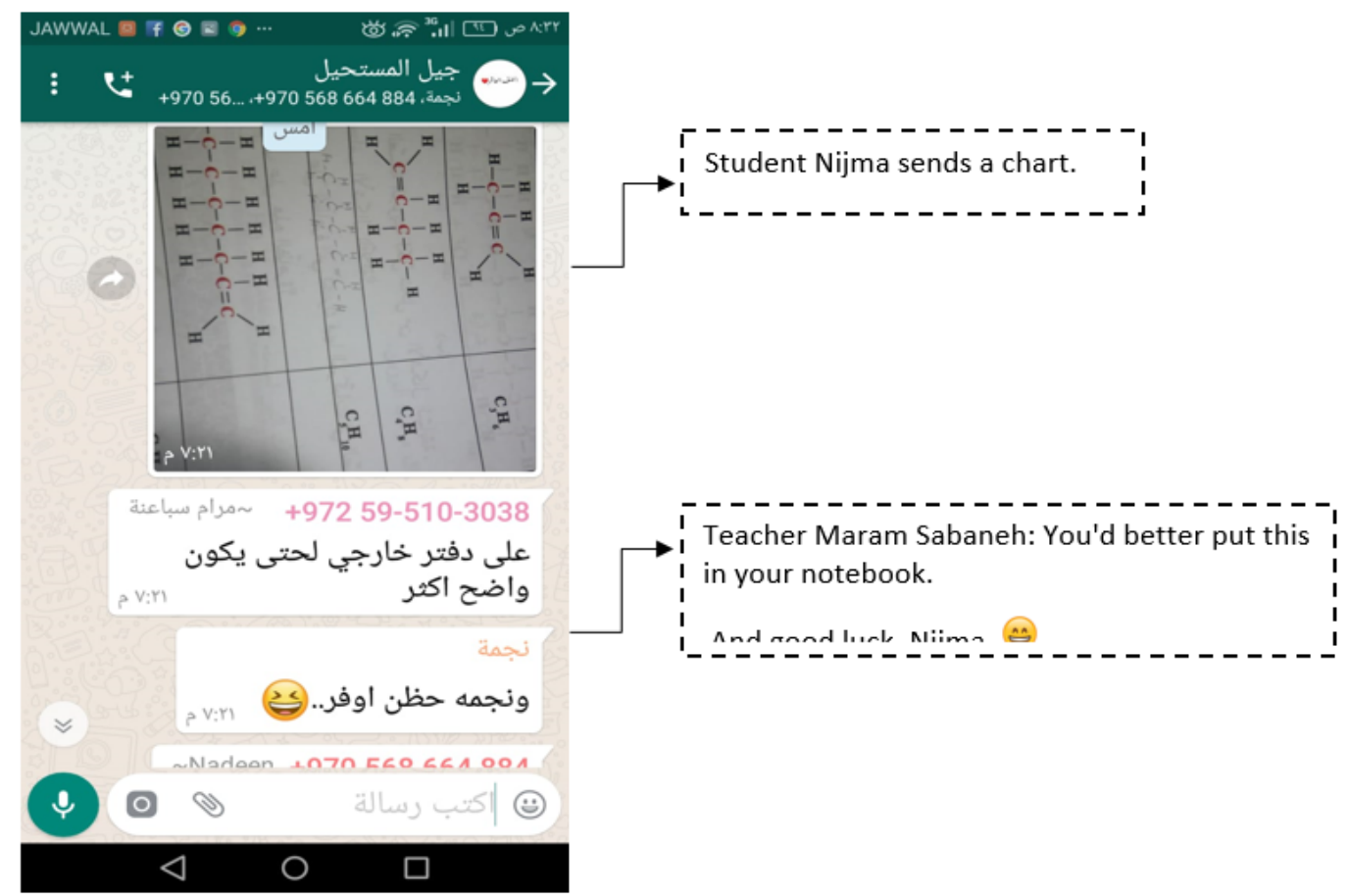

Figure 19. Relevance to Curriculum

\section{Relevance to real world}

Oftentimes, students tried to link what they learn to the real world around them- a point that many teachers unfortunately fail to notice. Many related studies have suggested that such linking should lie in the core of the teaching-learning process because failing to do so leaves students uncertain about the value from the knowledge they are gaining (Abualrob \& Daniel, 2011). The table also shows that $76 \%$ of the messages exchanged were related to real life. This is probably due to the comfort WhatsApp offers learners. Students using the application at home are more likely to be able to raise questions they think are relevant to real life experiences. The same students would be otherwise apprehended by the classroom environment, with the time allocated for a period might be insufficient and where students think that some questions might put them in embarrassing situations. 


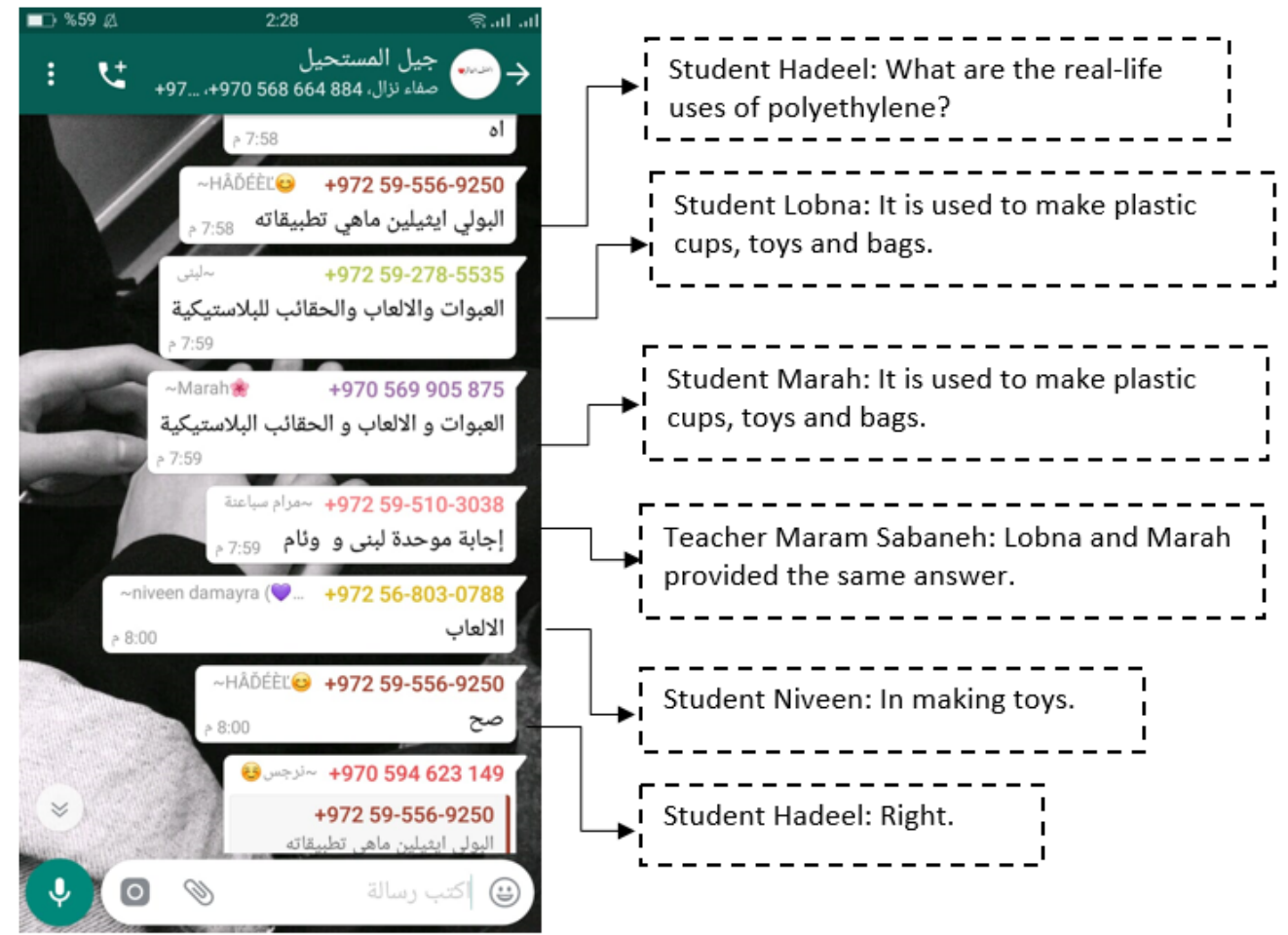

Figure 20. Relevance to Real World

\section{DISCUSSION AND CONCLUSION}

Vestiges of WhatsApp as a social networking site still affected how students used the application. This is evidenced by the data collected, showing students using WhatsApp more for social purposes (a lot of the messages exchanged between students were social in nature, such as salutation, jokes, entertainment, issues of shared concerns, and having fun). However, the portion of instruction-related messages was somehow enough to predict more effective future use of the application for teaching/learning purposes.

WhatsApp has great potentials as a social network; yet there is more to it than what its classification- as a social platform- suggests. Today, many teachers are familiar with WhatsApp, and they use it for different purposes, including socializing and staying in touch with friends and family. Probably, it is now time to use it for instruction. School students are also at home with WhatsApp, and many of them already use it for different purposes. This shared knowledge would make WhatsApp an actual tool in the teaching-learning process that is based on cooperation.

In large size classes, it is very hard for the learners to do the same tasks simultaneously, and it is also very difficult for the teacher to give them instantaneous feedback. WhatsApp might provide an effective solution to this problem. The teacher, together with students, can set up a WhatsApp group where students can send and receive messages within the group, with instant feedback always possible from the teacher. Likewise, for students with heavy schedule at school, communicating via WhatsApp can be an effective way for using available time in a wise manner. The analysis suggested that WhatsApp has enabled learners to exchange text messages, links, pictures, videos, and voice messages from the convenience of their homes.

We found the students capable of utilizing different strategies that WhatsApp has made available to them, including free unlimited messages; sending out questions to other students 
and the teachers; staying in contact with other students as well as with the teachers; receiving feedback from the teachers and classmates; exchanging thoughts about the topic in question; making free calls; and sending and receiving audio messages, pictures and videos.

The findings suggest that WhatsApp has proved to be effective in the instruction process, namely for organizing things (for example, what tasks come first); facilitating instructions (what is exactly required); and elaborating and expanding on classroom activities (extensive or probing communication).

In a WhatsApp environment, learners have the convenience of their private space in which they are not intimidated by the presence of other people in a traditional classroom environment. The application is particularly relevant when it comes to discussing some issues that might be considered as social taboos (for example, sex). WhatsApp was found to be effective because it maintains the privacy of the people involved, and things they exchange do not go public. What is more, people with special needs find in WhatsApp a window through which they can feel at ease communicating their thoughts and engaging themselves actively in discussions. The students' interaction was found to be rather encouraging, and it shouldn't be long before this will be integral to our education system.

Our findings also suggest that WhatsApp can be an effective tool for supporting e-learning, in particular because people within a closed group can focus on a subject which comes in handy for exchanging questions and answers. In this study, we saw students and teachers doing collaborative tasks in a timesaving environment. Further organization is, however, needed. Setting up groups in this regard should be effective, allowing for instant communication and sharing messages within the group. WhatsApp allows one-to-one communication, connects people in closed groups, facilitates interaction through rapid exchanges of text, images, audio and video on mobile phones. These features on WhatsApp can and should enhance the teachinglearning process.

Based on our findings, we recommend that WhatsApp be made a fundamental tool in the education process. This requires that different procedures done as prerequisites. First, it is important that teachers be trained on using the application effectively. Second, it is necessary that the Ministry of Education make related online materials/sources available in Arabic. Third, it would be imperative to empower students to be able to use WhatsApp for educational purposes, which first requires from them to be good miners of information that can later be shared on WhatsApp. Encouraging the use of WhatsApp in the Palestinian educational system should be made a top priority, as WhatsApp is probably the most effective, the most easily available method of communication outside the school environment. By carrying out this study, we hope that this work would help initiate further research initiatives into this important topic.

\section{REFERENCES}

Abualrob, M., \& Daniel, E. (2011). The Delphi Technique in Identifying Learning Objectives for the Development of Science, Technology and Society Modules for Palestinian Ninth Grade Science Curriculum. International Journal of Science Education, 35(15), 2538-2558. https://doi.org/10.1080/09500693.2011.610381

Asterhan, C. S., \& Rosenberg, H. (2015). The promise, reality and dilemmas of secondary school teacher-student interactions on Facebook: The teacher perspective. Computers \& Education, 85, 134-148. https://doi.org/10.1016/j.compedu.2015.02.003 
Boyd, D., \& Ellison, N. B. (2007). Social network sites: Definition, history, and scholarship. Journal of Computer-Mediated Communication, 13(1), 210-230. https://doi.org/10.1111/j.10836101.2007.00393.x

Constine, J. (2018, January 31). WhatsApp hits 1.5 billion monthly users. \$19B? Not so bad. Retrieved from https://techcrunch.com/2018/01/31/whatsapp-hits-1-5-billion-monthlyusers-19b-not-so-bad/

Fewkes, A. M., \& McCabe, M. (2012). Facebook: Learning tool or distraction? Journal of Digital Learning in Teacher Education, 28(3), 9298. https://doi.org/10.1080/21532974.2012.10784686

Friedman, L.W., \& Friedman, H. H. (2013). Using social media technologies to enhance online learning. Journal of Educators Online, 10(1). https://doi.org/10.9743/JEO.2013.1.5

iPoke. (2019, January 15). Social Palestine. Retrieved from http://social.ipoke.co/?fbclid= IwAR12SffWAdOY1Wn5AaVLYPBA5_p4iwNIOoxSm_ARGXbbfsyXoYQ2i6NWohw

Plana, M. G- C., Escofet, M. I. G., Figueras, I. T., Gimeno, A., Appel, C., \& Hopkins, J. (2013, July). Improving learners' reading skills through instant short messages: A sample study using WhatsApp. 4th World-CALL Conference, Glasgow. Retrieved from https://www.researchgate.net/publication/255718202_Improving_learners'_reading_sk ills_through_instant_short_messages_a_sample_study_using_WhatsApp

Rambe, P., \& Crispen C. (2013, August 23). Using mobile devices to leverage student access to collaboratively-generated resources: A case of WhatsApp instant messaging at a South African university. International Conference on Advanced Information and Technology for Education. Retrieved from https://www.researchgate.net/publication/266645202 Using_mobile_devices_to_leverage_student_access_to_collaboratively_generated_reso urces_A_case_of_WhatsApp_instant_messaging_at_a_South_African_University

Robert, L. \& Dennis, A. (2005). Paradox of richness: A cognitive model of media choice. IEEE Transactions of Professional Communication, 48(1), 10-21. http://doi.org/10.1109/TPC.2004.843292

Schwarz, B., \& Caduri, G. (2016). Novelties in the use of social networks by leading teachers in their classes. Computers \& Education, 102, 35-51. https://doi.org/10.1016/j.compedu.2016.07.002

Siemens, G. (2004, December 10). Constructivism: A learning theory for the digital age. Retrieved from http://www.itdl.org/journal/jan_05/article01.htm

Smit, I. (2011, November 12). WhatsApp with BlackBerry; Can messengers (BBM) be MXit? Retrieved from https://pdfs.semanticscholar.org/a126/55aae1de674c2147b2f5844450d c9a661c2a.pdf

Smith, E. E. (2016). A real double-edged sword: Undergraduate perceptions of social media in their learning. Computers \& Education, 103, 44-58. https://doi.org/10.1016/j.compedu.2016.09.009

Vygotsky, L. S. (1978). Mind in society: The development of higher psychological processes. Cambridge. MA: Harvard University Press.

Correspondence: Marwan Mohammad Abualrob, Arab American University, Palestine.

E-mail: marwan.abualrob@aaup.edu 